\title{
Predictors of the chest CT score in COVID-19 patients: a cross-sectional study
}

Niloofar Ayoobi Yazdi ${ }^{1 \dagger}$, Abdolkarim Haji Ghadery ${ }^{2 \dagger}$, SeyedAhmad SeyedAlinaghi ${ }^{3}$, Fatemeh Jafari ${ }^{4}$, Sirous Jafari ${ }^{4}$, Malihe Hasannezad ${ }^{4}$, Hamid Emadi Koochak ${ }^{4}$, Mohammadreza Salehi ${ }^{4}$, Seyed Ali Dehghan Manshadi ${ }^{4}$, Mohsen Meidani ${ }^{4}$, Mahboubeh Hajiabdolbaghi ${ }^{4}$, Zahra Ahmadinejad ${ }^{4}$, Hossein Khalili ${ }^{5}$, Mohammad-Mehdi Mehrabi Nejad ${ }^{2^{*}+}$ and Ladan Abbasian ${ }^{4^{*}+}$ (]

\begin{abstract}
Background: Since the COVID-19 outbreak, pulmonary involvement was one of the most significant concerns in assessing patients. In the current study, we evaluated patient's signs, symptoms, and laboratory data on the first visit to predict the severity of pulmonary involvement and their outcome regarding their initial findings.

Methods: All referred patients to the COVID-19 clinic of a tertiary referral university hospital were evaluated from April to August 2020. Four hundred seventy-eight COVID-19 patients with positive real-time reverse-transcriptasepolymerase chain reaction (RT-PCR) or highly suggestive symptoms with computed tomography (CT) imaging results with typical findings of COVID-19 were enrolled in the study. The clinical features, initial laboratory, CT findings, and short-term outcomes (ICU admission, mortality, length of hospitalization, and recovery time) were recorded. In addition, the severity of pulmonary involvement was assessed using a semi-quantitative scoring system (0-25).

Results: Among 478 participants in this study, 353 (73.6\%) were admitted to the hospital, and 42 (8.7\%) patients were admitted to the ICU. Myalgia (60.4\%), fever (59.4\%), and dyspnea (57.9\%) were the most common symptoms of participants at the first visit. A review of chest CT scans showed that Ground Glass Opacity (GGO) (58.5\%) and consolidation (20.7\%) were the most patterns of lung lesions. Among initial clinical and laboratory findings, anosmia $(P=0.01)$, respiratory rate $(R R)$ with a cut point of $25(P=0.001)$, C-reactive protein (CRP) with a cut point of $90(P=0.002)$, white Blood Cell (WBC) with a cut point of $10,000(P=0.009)$, and $\mathrm{SpO}_{2}$ with a cut point of $93(P=0.04)$ was associated with higher chest CT score. Lung involvement and consolidation lesions on chest $C T$ scans were also associated with a more extended hospitalization and recovery period.
\end{abstract}

\footnotetext{
*Correspondence: mm-mehrabinejad@alumnus.tums.ac.ir; la-abbasian@sina.

tums.ac.ir

${ }^{\dagger}$ Niloofar Ayoobi Yazdi and Abdolkarim Haji Ghadery are joint first authors

†Ladan Abbasian and Mohammad-Mehdi Mehrabi Nejad are joint senior

authors

${ }^{2}$ Department of Radiology, Advanced Diagnostic and Interventional

Radiology Research Center(ADIR), Tehran University of Medical Sciences,

Tehran, Iran

${ }^{4}$ Department of Infectious Diseases, Imam Khomeini Hospital, Imam

Khomeini Hospital Complex, Tehran University of Medical Sciences, Blv.

Keshavarz, Tehran, Iran

Full list of author information is available at the end of the article
}

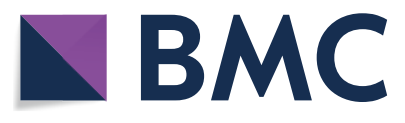

(c) The Author(s) 2021, corrected publication 2021. Open Access This article is licensed under a Creative Commons Attribution 4.0 International License, which permits use, sharing, adaptation, distribution and reproduction in any medium or format, as long as you give appropriate credit to the original author(s) and the source, provide a link to the Creative Commons licence, and indicate if changes were made. The images or other third party material in this article are included in the article's Creative Commons licence, unless indicated otherwise in a credit line to the material. If material is not included in the article's Creative Commons licence and your intended use is not permitted by statutory regulation or exceeds the permitted use, you will need to obtain permission directly from the copyright holder. To view a copy of this licence, visit http://creativecommons.org/licenses/by/4.0/. The Creative Commons Public Domain Dedication waiver (http://creativecommons.org/publicdomain/zero/1.0/) applies to the data made available in this article, unless otherwise stated in a credit line to the data. 
Conclusions: Initial assessment of COVID-19 patients, including symptoms, vital signs, and routine laboratory tests, can predict the severity of lung involvement and unfavorable outcomes.

Keywords: COVID-19, Computed tomography, Outcome, Recovery, Chest CT score

\section{Background}

The coronavirus disease (COVID-19), caused by a novel coronavirus named severe acute respiratory syndrome coronavirus2 (SARS-CoV-2), has spread to 223 countries with more than 186 million confirmed cases and more than 4 million deaths (World Health Organization) [1]. SARS-CoV-2 shares similarities in disease dynamics, transmission route, and cell entry receptors, angiotensinconverting enzyme 2 (ACE2) with severe acute respiratory syndrome coronavirus (SARS-CoV) [2-4].

Person-to-person transmission of SARS-CoV-2 occurs with respiratory droplets from an infected person to others. Viral shedding may occur 1-2 days before the onset of symptoms and may continue for 1-2 weeks in mild to moderate cases or go beyond two weeks in severe cases[5, 6]. Symptoms usually appear between 2 and 14 days after exposure; The common initial symptoms of COVID-19 are fever, cough, fatigue, and dyspnea [7, 8], with more specific symptoms, including loss of taste and smell [6]. SARS-CoV-2 targets multiple organs, including respiratory, cardiac, and renal systems causing pneumonia and respiratory failure in patients $[9,10]$. In addition, systemic inflammatory response syndrome and cytokine storm contribute to multi-organ failure and coagulopathy in critical patients with COVID-19 [11, 12].

Computed tomography $(\mathrm{CT})$ is the most sensitive tool for diagnosing COVID-19, and several radiological patterns are seen in different phases of disease [13, 14]. Among different patterns of chest CT scan, groundglass opacities (GGO) and mixed GGO with consolidation is reported as the most common patterns in COVID-19 patients [15]. Although definite diagnosis relies on real-time reverse-transcriptase-polymerase chain reaction (RT-PCR) [16], chest CT is a valuable modality to measure the extent of lung involvement and propose a treatment plan.

Initial assessment of COVID-19 patients is essential for further management. In this study, we assessed the patient's signs, symptoms, laboratory tests, and imaging findings to identify which initial clinical and laboratory findings may predict the severity of lung involvement and, accordingly, short-term outcome.

\section{Method}

\section{Study design and participants}

The study protocol and consent notes were reviewed and approved by the ethics board of our institute (approval code: TUMS.VCR.REC.1399.138). This study is a crosssectional, observational, single-center study conducted between April and August 2020 at a tertiary medical center. All referred patients to the COVID-19 clinic of Imam Khomeini Hospital, university hospital, were evaluated for eligibility of participation in the study. Patients with mild, moderate, or severe clinical symptoms suggestive of COVID-19 who had positive RT-PCR (226, $47.2 \%)$ confirming COVID-19 or suggestive chest CT scan $(252,52.8 \%)$ were included after signing a written informed consent form. Patients with history of previous lung diseases excluded from study. Four physicians did the patient examination and data registration, and five medical residents followed up with the patients through telephone calls. Both hospitalized (after discharge) and outpatient participants were followed weekly through telephone calls until symptoms resolved. Treatment regimens were based on the latest version of the national protocol of COVID-19.Hydroxychloroquine was used as the primary therapeutic option in the outpatient setting; hydroxychloroquine, lopinavir/ritonavir (Kaletra), atazanavir (nonboosted with ritonavir or cobicistat) were administered for hospitalized patients, and in case of severe hypoxemia (not attaining $\mathrm{SpO} 2$ of $>88 \%$ with reservoir mask), corticosteroid was given.

\section{Data collection}

Following clinical data were collected in the specific forms for each patient, including: (a) demographics information: (age and sex); (b) vital signs: temperature ( $\mathrm{T}-\mathrm{Cel}-$ sius), oxygen saturation $\left(\mathrm{SpO}_{2}\right)$, respiratory rate (RR per minute), and pulse rate (PR per minute); (c) symptoms: myalgia, generalized weakness, fever, chills, headache, chest pain, dyspnea, sore throat, cough, sputum, loss of appetite, loss of taste, anosmia; (d) comorbidities: hypertension (HTN), diabetes mellitus (DM); (e) laboratory data: white blood cell (WBC-cell/mm3), lymphocyte count (cell $/ \mathrm{mm} 3)$, platelet(cell $/ \mathrm{mm} 3)$, C-reactive protein (CRP-mg/L), erythrocyte sedimentation rate (ESR-mm/ $\mathrm{hr}$ ), and lactate dehydrogenase (units/L); (f) admission status: inpatient or outpatient; (g) Intensive care unit (ICU) admission; (h) death; (i) radiologic findings (will be mentioned in following section); (j) length of hospitalization (day) and recovery time (day). The recovery time was defined as the patient's subjective statement indicating no symptoms other than his/her baseline. 


\section{Chest CT protocols and interpretation}

All chest CT scans were performed on either lightspeed 64-detector CT (GE Healthcare) or the 16-slice (Siemens SOMATOM Emotion) MDCT scanner with patients in the supine position at full inspiration breath-hold. The leading scanning parameters were as follows: $120 \mathrm{kVp}$ tube voltage; $50-150 \mathrm{mAs}$ tube current; $0.75 \mathrm{~s}$ tube rotation time; $0.5-0.75 \mathrm{~s}$ gantry rotation time; $2-3-\mathrm{mm} \mathrm{sec-}$ tion thickness; and $0.6-2 \mathrm{~mm}$ beam collimation.

The visual chest $\mathrm{CT}$ interpretation was performed using a single, experienced (10 years) thoracic radiologist. The radiologist was blinded to clinical and laboratory data of participants and reviewed on both lung and mediastinal window settings. The presence of $\mathrm{CT}$ features including (a) predominant pattern of lesions: groundglass opacification (GGO), consolidation, or mixed GGO and consolidation; (b) dominant distribution of lesions: central, peripheral, diffuse, or peri- broncho vascular; (c) shape of lesions: round, elongated, wedged, or confluent; (d) additional findings: crazy paving pattern, reverse-halo sign, interlobular septal thickening, linear opacities combined, air bronchogram sign, tree in bud, adjacent pleural thickening, pleural effusion, pericardial effusion, lymphadenopathy, and pulmonary emphysema, was reported as defined in Fleischner Society Glossary of terms for Thoracic Imaging [17].

To quantify the extension of lung lesions, a scoring system as follows was used: each of the five lobes of lungs visually scored from 0 to 5 ( 0 , no involvement; $1,<5 \%$ involvement; $2,5-25 \%$ involvement; $3,26-49 \%$ involvement; 4, 50-75\% involvement; $5,>75 \%$ involvement). Then, the total chest $\mathrm{CT}$ score was calculated by the sum of each lob's scores, ranging from 0 to 25 [18].

\section{Statistical analysis}

The statistical analysis was performed using SPSS version 16 (SPSS Inc. Chicago, IL). Continuous variables were presented as mean (standard deviation), and categorical variables as frequency and percentages. Variables were tested for normality using Kolmogorov-Smirnov test. Normally distributed continuous variables were analyzed using the independent sample $t$-test; otherwise, the Mann-Whitney $U$ test was used. A Chi-square test was employed for nominal variables. $P$ values less than 0.05 were considered statistically significant.

\section{Results}

\section{Participant's characteristic}

A total of 478 participants were recruited in the current study with convenient sampling. Of those, 353 (73.6\%) participants were admitted to the hospital, and among hospitalized participants, $42(8.7 \%)$ were admitted to
ICU. The patient's mean age was 53.92 (15.4), and 267 (55.8\%) was male. The most common complaints of patients were myalgia (60.4\%), fever (59.4\%), dyspnea (57.9\%), chills (49.5\%), and generalized weakness (45.3\%). Demographics, initial signs, symptoms, and laboratory data of all participants are listed (Table 1).

\section{Chest CT scan findings}

The most common patterns of pulmonary involvement were GGO (58.5\%) and consolidation 99 (20.7\%) with peri-broncho-vascular (33.7\%), peripheral (33\%), and diffuse (32\%) distribution, and the most common shape of lesions were confluent (47.2\%). Detailed chest CT scan findings are presented (Table 2).

Our results showed that the total chest CT score was significantly higher in patients with anosmia (mean of $12.46 \pm 7.73$ vs. $8.73 \pm 8.33 ; P=0.01$ ), and had a significant positive association with $\mathrm{RR}$ with a cut point of 25 (mean of $8.37 \pm 7.94$ vs. $12.37 \pm 9.23 ; P=0.001$ ), CRP with a cut point of 90 (mean of $7.82 \pm 7.89$ vs. $10.83 \pm 8.67 ; P=0.002), \mathrm{WBC}$ with a cut point of 10,000 (mean of $8.70 \pm 8.33$ vs. $12.02 \pm 8.17 ; P=0.009$ ) and negative association with $\mathrm{SpO} 2$ with a cut point of 93 (mean of $9.75 \pm 8.54$ vs. $7.76 \pm 7.58 ; P=0.04$ ). Chest $C T$ score was also associated with a higher risk of ICU admission (mean of $11.10 \pm 9$ vs. $7.71 \pm 7.88 ; P=0.003$ ), longer hospital stay (mean of $9.08 \pm 8.23$ vs. $12 \pm 9.21 ; P=0.037$ ) and recovery period (mean of $7.28 \pm 8.02$ vs. $9.29 \pm 8.09$; $P=0.009$ ) (Table 3).

Further analysis showed consolidation on chest CT scan had a significant association with initial lower $\mathrm{SpO} 2$ $(P=0.001)$, higher risk of ICU admission $(P=0.005)$, extended hospitalization $(P=0.003)$, and longer recovery time $(P=0.008)$ (Table 4$)$.

\section{Discussion}

As treatment protocols are based on the extent of lung involvement, assessing the severity of pulmonary involvement is crucial in determining the treatment plan for COVID-19 infected patients. Chest CT scan is not available everywhere, and its usage is sometimes limited, especially in pregnant patients. Therefore, physicians need prompt assessment according to patient's initial signs and symptoms and routine laboratory tests for timely management. In the current study, we assessed clinical and laboratory findings on the first visit to predict the extent of lung involvement in COVID-19 patients. We found that patients with anosmia, lower $\mathrm{SpO} 2(<93)$, and higher respiratory rate ( $>25$ per minute), WBC count $(>10,000$ cells/mm3), CRP (>90 mg/Liter) had higher total CT scores. Besides, consolidation opacities as the worst lung lesions were more commonly detected in patients 
Table 1 Detail of demographic data and baseline signs, symptoms, and laboratory findings of all studied participants

\begin{tabular}{|c|c|}
\hline Variables & All patients $N=478$ \\
\hline \multicolumn{2}{|l|}{ Demographics } \\
\hline Age (years) & $53.92(15.4)$ \\
\hline$<39$ & $90(18.8 \%)$ \\
\hline $39-49$ & $102(21.3 \%)$ \\
\hline $50-59$ & $104(21.7 \%)$ \\
\hline $60-69$ & $98(20.5 \%)$ \\
\hline$\geq 70$ & $84(17.5 \%)$ \\
\hline Gender (male) & $267(55.8 \%)$ \\
\hline \multicolumn{2}{|l|}{ Symptoms on the first visit } \\
\hline Myalgia & $289(60.4 \%)$ \\
\hline Generalized weakness & $217(45.3 \%)$ \\
\hline Fever & $284(59.4 \%)$ \\
\hline Chills & $237(49.5 \%)$ \\
\hline Headache & $134(28 \%)$ \\
\hline Chest pain & $126(26.3 \%)$ \\
\hline Dyspnea & $277(57.9 \%)$ \\
\hline Sore throat & $80(16.7 \%)$ \\
\hline Cough & $334(69.8 \%)$ \\
\hline Sputum & $15(3.1 \%)$ \\
\hline Loss of appetite & $194(40.5 \%)$ \\
\hline Loss of taste & $48(10 \%)$ \\
\hline Anosmia & $60(12.5 \%)$ \\
\hline \multicolumn{2}{|l|}{ Vital signs on first visit } \\
\hline \multicolumn{2}{|l|}{ Temperature $\left({ }^{\circ} \mathrm{C}\right)$} \\
\hline$\leq 37.2$ & $212(44.3 \%)$ \\
\hline$\geq 37.3$ & $266(55.7 \%)$ \\
\hline \multicolumn{2}{|l|}{$\mathrm{O} 2$ saturation $\%$} \\
\hline$\geq 93$ & $276(57.7 \%)$ \\
\hline$<93$ & $202(42.3 \%)$ \\
\hline \multicolumn{2}{|c|}{ Respiratory rate (breaths/minute) } \\
\hline$<25$ & $389(81.3 \%)$ \\
\hline$\geq 25$ & $89(18.7 \%)$ \\
\hline \multicolumn{2}{|c|}{ Initial laboratory findings } \\
\hline \multicolumn{2}{|c|}{ White blood cell (WBC) (cell/ mm³) } \\
\hline$<4000$ & $51(10.6 \%)$ \\
\hline 4000-9999 & $364(76.3 \%)$ \\
\hline$\geq 10,000$ & $63(13.1 \%)$ \\
\hline \multicolumn{2}{|c|}{ Lymphocyte count (cell/ mm³) } \\
\hline$\leq 1000$ & $103(21.5 \%)$ \\
\hline$>1000$ & $375(78.5 \%)$ \\
\hline \multicolumn{2}{|l|}{ Platelet (cell/mm³) } \\
\hline$<150,000$ & $82(17.1 \%)$ \\
\hline$\geq 150,000$ & $396(82.9 \%)$ \\
\hline \multicolumn{2}{|c|}{ C-reactive protein (CRP) (mg/L) } \\
\hline$\leq 90$ & $17(3.5 \%)$ \\
\hline$\geq 91$ & $461(96.5 \%)$ \\
\hline \multicolumn{2}{|c|}{ Erythrocyte sedimentation rate (ESR) $(\mathrm{mm} / \mathrm{h})$} \\
\hline$\leq 60$ & $13(2.7 \%)$ \\
\hline$\geq 61$ & $465(97.3 \%)$ \\
\hline
\end{tabular}

Table 1 (continued)

\begin{tabular}{lc}
\hline Variables & All patients $\mathbf{N}=\mathbf{4 7 8}$ \\
\hline Lactate dehydrogenase (LDH) (units/L) & \\
$\quad<480$ & $65(13.5 \%)$ \\
$\quad \geq 480$ & $413(86.5 \%)$ \\
Underlying disease & \\
DM & $132(27.6 \%)$ \\
HTN & $136(28.4 \%)$ \\
\hline
\end{tabular}

All variables are reported as $\mathrm{N}(\%)$

HTN: hypertension, DM: diabetesmellitus

with lower initial $\mathrm{SpO} 2$ or admitted to ICU. Moreover, patients with consolidation on their chest $\mathrm{CT}$ scan experienced extended hospitalization $(\geq 15)$ and recovery period ( $\geq 15)$. A higher chest CT score was also associated with more extended hospitalization and recovery time.

\section{Predictors of severe lung involvement}

In line with previous studies, our results showed that higher initial WBC and CRP are associated with more severe cases of COVID-19 patients, as WBC $>1000$ cell/ $\mathrm{mm} 3$ and $\mathrm{CRP}>90 \mathrm{mg} / \mathrm{L}$ were associated with higher chest CT scores. Similar to our findings, Salvatore et al. reported hospitalized and critical COVID-19 patients had higher CRP, leukocyte count, neutrophils, LDH, D-dimer, and troponin [19]. Zhang et al. also reported that chest CT score positively associated with WBC count, CRP, ESR, procalcitonin, and abnormal coagulation function [20].

Among several clinical symptoms on the first visit, just anosmia was associated with extended pulmonary involvement. A literature review did not show any previous report of extended lung involvement in patients with anosmia, and our study is the first to report this correlation. Association of anosmia and pulmonary involvement can be justified by the roll ofchemokines, as previous reports defined CXCL10 contribution in both cytokine storm of COVID-19 patients causing acute respiratory distress syndrome (ARDS) and demyelination process of the olfactory nerve causing anosmia [21].

Several clinical signs of patients on the first visit, including higher $\mathrm{RR}$ and lower $\mathrm{SpO} 2$, were associated with higher total chest CT scores. Lower SpO2 was also associated with consolidation opacities as the most severe lesion of COVID-19 in chest CT scan. In line with our findings, Kunwei $\mathrm{Li}$ et al. also showed that patients with $\mathrm{RR} \geq 30$ times/min, and $\mathrm{SpO} 2 \leq 93 \%$ as categorized in severe type patients, had significantly higher total chest CT scores than common type patients [22]. Another study also confirmed that severe/critical 
Table 2 Radiological findings in all studied participants

\begin{tabular}{|c|c|}
\hline Variables & All patients $N=478$ \\
\hline \multicolumn{2}{|l|}{ Pulmonary involvement scores* } \\
\hline RUL Total Score & $1.57(1.75)$ \\
\hline RML Total Score & $1.26(1.71)$ \\
\hline RLL Total Score & $1.91(1.84)$ \\
\hline LUL Total Score & $1.56(1.72)$ \\
\hline LLL Total Score & $1.79(1.84)$ \\
\hline Total pulmonary involvement Score & $8.11(8.08)$ \\
\hline \multicolumn{2}{|l|}{ Frequency of lobe involvement } \\
\hline RUL & $266(55.5 \%)$ \\
\hline RML & $225(47 \%)$ \\
\hline RLL & $304(63.5 \%)$ \\
\hline LUL & $274(57.3 \%)$ \\
\hline LLL & $287(60 \%)$ \\
\hline \multicolumn{2}{|l|}{ Laterality of lung involvement } \\
\hline Unilateral & $52(10.8 \%)$ \\
\hline Bilateral & $286(59.8)$ \\
\hline \multicolumn{2}{|l|}{ Pattern of lesions } \\
\hline GGO & $280(58.5 \%)$ \\
\hline Consolidation & $99(20.7 \%)$ \\
\hline Mixed GGO and consolidation & $78(16.3 \%)$ \\
\hline \multicolumn{2}{|l|}{ Dominant distribution of lesions } \\
\hline Peripheral & $158(33 \%)$ \\
\hline Central & $6(1.3 \%)$ \\
\hline Diffuse & $153(32 \%)$ \\
\hline Peri broncho vascular & $161(33.7 \%)$ \\
\hline \multicolumn{2}{|l|}{ Shape of lesions } \\
\hline Round & $73(15.2 \%)$ \\
\hline Elongated & $82(17.1 \%)$ \\
\hline Wedged & $183(38.2 \%)$ \\
\hline Confluent & $226(47.2 \%)$ \\
\hline \multicolumn{2}{|l|}{ Additional findings } \\
\hline Crazy paving pattern & 87 (31\%) \\
\hline Reverse-halo & $14(2.9 \%)$ \\
\hline Interlobular septal thickening & $20(4.1 \%)$ \\
\hline Linear opacities combined & $81(16.9 \%)$ \\
\hline Air bronchogram sign & $114(23.8 \%)$ \\
\hline Tree in bud & $15(3.1 \%)$ \\
\hline Adjacent pleura thickening & $15(3.1 \%)$ \\
\hline Pleural effusion & $27(5.6 \%)$ \\
\hline Unilateral & $12(2.5 \%)$ \\
\hline Bilateral & $15(3.1 \%)$ \\
\hline Pericardial effusion & $10(2 \%)$ \\
\hline Lymphadenopathy & $7(1.4 \%)$ \\
\hline Pulmonary emphysema & $10(2 \%)$ \\
\hline
\end{tabular}

RUL, right upper lobe; RML, right middle lobe; RLL, right lower lobe; LUL, left upper lobe; LLL, left lower lobe

*Pulmonary involvement scores are reported as mean (standard deviation); all other variables are reported as $\mathrm{N}(\%)$
Table 3 Demographic, clinical, laboratory findings, and outcomes of patients with COVID-19 based on the total chest CT scan score

\begin{tabular}{|c|c|c|c|}
\hline Variables & All patients $=478$ & $\begin{array}{l}\text { Total CT } \\
\text { score } \\
\text { Mean } \pm \text { SD }\end{array}$ & $P$ value \\
\hline \multicolumn{4}{|c|}{ Demographic data } \\
\hline \multicolumn{4}{|l|}{ Age (years) } \\
\hline$<39$ & 90 (18.8\%) & $10.47 \pm 8.02$ & $0.54^{\mathrm{a}}$ \\
\hline $39-49$ & $102(21.3 \%)$ & $8.15 \pm 8.19$ & \\
\hline $50-59$ & $104(21.7 \%)$ & $9.96 \pm 9.03$ & \\
\hline $60-69$ & $98(20.5 \%)$ & $9.57 \pm 8.23$ & \\
\hline$\geq 70$ & $84(17.5 \%)$ & $8.44 \pm 8.04$ & \\
\hline \multicolumn{4}{|l|}{ Sex } \\
\hline Male & $267(55.8 \%)$ & $7.70 \pm 7.84$ & 0.193 \\
\hline Female & $211(44.2 \%)$ & $8.67 \pm 8.37$ & \\
\hline \multicolumn{4}{|c|}{ Symptoms on first visit } \\
\hline \multicolumn{4}{|l|}{ Fever } \\
\hline Yes & $284(59.4 \%)$ & $9.06 \pm 8.25$ & 0.78 \\
\hline No & $194(40.6 \%)$ & $9.34 \pm 8.53$ & \\
\hline \multicolumn{4}{|l|}{ Dyspnea } \\
\hline Yes & $277(57.9 \%)$ & $9.56 \pm 8.58$ & 0.20 \\
\hline No & $201(42.1 \%)$ & $8.38 \pm 7.82$ & \\
\hline \multicolumn{4}{|l|}{ Sputum } \\
\hline Yes & $15(3.1 \%)$ & $9.64 \pm 9.70$ & 0.87 \\
\hline No & $463(96.9 \%)$ & $9.14 \pm 8.30$ & \\
\hline \multicolumn{4}{|l|}{ Cough } \\
\hline Yes & $334(69.8 \%)$ & $9.10 \pm 8.20$ & 0.85 \\
\hline No & $144(30.2 \%)$ & $9.29 \pm 8.68$ & \\
\hline \multicolumn{4}{|l|}{ Chest pain } \\
\hline Yes & $126(26.3 \%)$ & $9.42 \pm 8.08$ & 0.74 \\
\hline No & $352(73.7)$ & $9.07 \pm 8.43$ & \\
\hline \multicolumn{4}{|l|}{ Anosmia } \\
\hline Yes & 60 (12.5\%) & $12.46 \pm 7.73$ & $0.01^{*}$ \\
\hline No & $418(87.5 \%)$ & $8.73 \pm 8.33$ & \\
\hline \multicolumn{4}{|c|}{ Vital signs on first visit } \\
\hline \multicolumn{4}{|c|}{ Temperature $\left({ }^{\circ} \mathrm{C}\right)$} \\
\hline$\leq 37.2$ & $212(44.3 \%)$ & $9.00 \pm 8.37$ & 0.76 \\
\hline$\geq 37.3$ & $266(55.7 \%)$ & $9.28 \pm 8.35$ & \\
\hline \multicolumn{4}{|c|}{$\begin{array}{l}\text { Respiratory rate(breath/ } \\
\text { minute) }\end{array}$} \\
\hline$<25$ & $389(81.3 \%)$ & $8.37 \pm 7.94$ & $0.001^{*}$ \\
\hline$\geq 25$ & $89(18.7 \%)$ & $12.37 \pm 9.23$ & \\
\hline \multicolumn{4}{|l|}{ SpO2\% } \\
\hline$\geq 93$ & $276(57.7 \%)$ & $7.76 \pm 7.58$ & $0.04^{*}$ \\
\hline$<93$ & $202(42.3 \%)$ & $9.75 \pm 8.54$ & \\
\hline \multicolumn{4}{|c|}{ Initial laboratory findings } \\
\hline \multicolumn{4}{|c|}{ WBC (cell/ mm³) } \\
\hline$\leq 10,000$ & $415(86.9 \%)$ & $8.70 \pm 8.33$ & $0.009^{*}$ \\
\hline$>10,000$ & $63(13.1 \%)$ & $12.02 \pm 8.17$ & \\
\hline \multicolumn{4}{|c|}{$\begin{array}{l}\text { Lymphocyte count(cell/ } \\
\mathrm{mm}^{3} \text { ) }\end{array}$} \\
\hline$\leq 1000$ & $103(21.5 \%)$ & $9.77 \pm 8.88$ & 0.42 \\
\hline
\end{tabular}


Table 3 (continued)

\begin{tabular}{|c|c|c|c|}
\hline Variables & All patients $=478$ & $\begin{array}{l}\text { Total CT } \\
\text { score } \\
\text { Mean } \pm \text { SD }\end{array}$ & $P$ value \\
\hline$>1000$ & $375(78.5 \%)$ & $8.91 \pm 8.07$ & \\
\hline \multicolumn{4}{|c|}{ CRP (mg/L) } \\
\hline$\leq 90$ & $17(3.5 \%)$ & $7.82 \pm 7.89$ & $0.002^{*}$ \\
\hline 91 & $461(96.5 \%)$ & $10.83 \pm 8.67$ & \\
\hline \multicolumn{4}{|c|}{$\mathrm{ESR}(\mathrm{mm} / \mathrm{h})$} \\
\hline$\leq 60$ & $13(2.7 \%)$ & $8.24 \pm 8.45$ & 0.10 \\
\hline$\geq 61$ & $465(97.3 \%)$ & $10.05 \pm 8.54$ & \\
\hline \multicolumn{4}{|c|}{ LDH (units/L) } \\
\hline$<480$ & $65(13.5 \%)$ & $9.02 \pm 7.92$ & 0.12 \\
\hline$\geq 480$ & $413(86.5 \%)$ & $11.02 \pm 8.64$ & \\
\hline \multicolumn{4}{|c|}{ Underlying disease } \\
\hline \multicolumn{4}{|c|}{$\mathrm{DM}$} \\
\hline Yes & $132(27.6 \%)$ & $8.54 \pm 8.10$ & 0.35 \\
\hline No & $346(72.4 \%)$ & $9.42 \pm 8.45$ & \\
\hline \multicolumn{4}{|l|}{ HTN } \\
\hline Yes & $136(28.4 \%)$ & $9.11 \pm 8.30$ & 0.92 \\
\hline No & $342(71.6 \%)$ & $9.22 \pm 8.36$ & \\
\hline \multicolumn{4}{|l|}{ Outcomes } \\
\hline \multicolumn{4}{|c|}{ ICU admission } \\
\hline Yes & $42(8.7 \%)$ & $11.10 \pm 9$ & $0.003^{*}$ \\
\hline No & $436(92.2 \%)$ & $7.71 \pm 7.88$ & \\
\hline \multicolumn{4}{|c|}{ Recovery time (days) } \\
\hline$<15$ & $278(58.1 \%)$ & $7.28 \pm 8.02$ & $0.009^{*}$ \\
\hline$\geq 15$ & $200(41.9 \%)$ & $9.29 \pm 8.09$ & \\
\hline \multicolumn{4}{|c|}{$\begin{array}{l}\text { Hospitalization time } \\
\text { (days) }\end{array}$} \\
\hline$<15$ & $437(91.4 \%)$ & $9.08 \pm 8.23$ & $0.037^{*}$ \\
\hline$\geq 15$ & $41(8.6 \%)$ & $12 \pm 9.21$ & \\
\hline \multicolumn{4}{|l|}{ Death } \\
\hline Yes & $16(3.3 \%)$ & $8.51 \pm 1.85$ & 0.86 \\
\hline No & $462(96.7 \%)$ & $8.05 \pm 0.37$ & \\
\hline
\end{tabular}

HTN, hypertension; DM, diabetes mellitus; SpO2, oxygen saturation; WBC, white blood cell; LDH, lactate dehydrogenase; CRP, C-reactive protein; ESR, erythrocyte sedimentation rate; $\mathrm{ICU}$, intensive care unit

*Statistically significant $(p$ value $<0.05$ )

a One way ANOVA test is used; independent $\mathrm{t}$-test or Mann-Whitney $\mathrm{U}$ test used for all other comparisons

patients with respiratory rate $\geq 30$ times/min and $\mathrm{SpO} 2$ of $93 \%$ or less in a resting state had higher total CT scores than ordinary COVID-19 patients [23]. Aalinezhad [24] and Osman[25] et al. also reported higher chest CT score is inversely associated with $\mathrm{O} 2$ saturation. Furthermore, a multicenter cohort study demonstrated that consolidation in upper lungs on the initial chest CT of COVID-19 patients was associated with increased odds of adverse endpoints, including $\mathrm{SpO} 2<93 \%$ and partial arterial pressure of oxygen less than $60 \mathrm{~mm} \mathrm{Hg}$ on room air [26].

\section{Chest CT predictors of unfavorable outcomes}

We found that ICU admission, more extended hospitalization, and recovery period were associated with higher total CT scores and consolidation opacities in chest CT of these patients. Similarly, a previous study showed a higher pulmonary score $\geq$ of 8 accompanied by age $\geq 53$, and $\mathrm{SpO}_{2} \leq 91$ predicts ICU admission and mortality [27]. Deepak Nagra et al. also reported a higher lung opacification score is a reliable predictor of ICU admission for COVID-19 patients [28]. Another study on baseline chest CT scans and clinical and laboratory data of 72 patients admitted with COVID-19 pneumonia showed lung severity score > was associated with a significantly lower recovery rate and discharge and extended hospitalization in patients admitted for COVID-19 pneumonia [29]. Similar to our findings, Ahlstrand et al. previously reported that chest $\mathrm{CT}$ score at hospital admission correlates closely with hospital length of stay and ICU admission [30]. CT severity score combined with age and history of at least one underlying disease had $79.7 \%$ sensitivity and $65.5 \%$ specificity in predicting the adverse outcomes in a previous study [31].

Initial assessment of patients in the clinic determines the treatment plan, so we assessed lung involvement based on initial signs, symptoms, and laboratory tests. Taken together, we found that patients with anosmia, higher respiratory rate, WBC count, or CRP, and lower $\mathrm{SpO} 2$ had extended pulmonary involvement of COVID19 pneumonia, which can cause adverse outcomes, including more extended hospitalization and recovery period. Hence, those patients should be prioritized for greater attention and intensive care.

\section{Limitations}

As recovery time was defined as a subjective statement of patients, this could have resulted in a conclusion error; inviting the patients to the clinic for evaluation could have been more precise to confirm recovery. In addition, in this study, we assessed just the presence of symptoms, not their severity; we recommend further studies assessing the severity of symptoms and their correlation with lung involvement or adverse outcomes.

\section{Conclusion}

Extended lung involvement of COVID-19 pneumonia can be predicted in clinics with patient's initial symptoms, vital signs, and laboratory tests, including anosmia, low SpO2, high RR, WBC, and CRP. Therefore, these 
Table 4 Details of demographic and clinical data of patients with or without consolidation

\begin{tabular}{|c|c|c|c|c|}
\hline Variables & All patients $N=478$ & With consolidation $\mathrm{N}=99$ & $\begin{array}{l}\text { Without consolidation } \\
\mathrm{N}=379\end{array}$ & $P$ value \\
\hline \multicolumn{5}{|l|}{ Demographic data } \\
\hline Age & $53.92(15.4)$ & $51.96(15.6)$ & $54.62(15.6)$ & 0.14 \\
\hline \multicolumn{5}{|l|}{ Gender } \\
\hline Male & $267(55.8 \%)$ & $55(11.5 \%)$ & $212(44.3 \%)$ & $0.94^{\mathrm{a}}$ \\
\hline Female & $211(44.2 \%)$ & $44(20.8 \%)$ & $167(23.4 \%)$ & \\
\hline \multicolumn{5}{|l|}{ Clinical data } \\
\hline Temperature $\left({ }^{\circ} \mathrm{C}\right)$ & $37.49(0.7)$ & $37.56(0.7)$ & $37.47(0.7)$ & 0.29 \\
\hline Respiratory rate (breath /per minute) & $21.65(5.1)$ & $22.18(6)$ & $21.41(4.9)$ & 0.19 \\
\hline $\mathrm{SpO} 2$ & $91.07(5.4)$ & $89.39(6.4)$ & $91.47(5.3)$ & $0.001^{*}$ \\
\hline WBC (cell/mm³) & $7.74(5.1)$ & $7.88(5.6)$ & $7.29(4.2)$ & 0.32 \\
\hline Lymphocyte count(cell/mm³) & $1372.8(1341.3)$ & $1375.5(1876.5)$ & $1279(870)$ & 0.56 \\
\hline $\mathrm{LDH}(\mathrm{U} / \mathrm{L})$ & $640.8(302.4)$ & $624.6(266.4)$ & $630.1(302.4)$ & 0.90 \\
\hline CRP (mg/L) & $96.90(76.2)$ & $105.97(69.6)$ & $90.82(77)$ & 0.13 \\
\hline $\mathrm{ESR}(\mathrm{mm} / \mathrm{h})$ & $74.06(32.2)$ & $77.34(33.3)$ & $71.23(31.2)$ & 0.16 \\
\hline \multicolumn{5}{|l|}{ Underlying disease } \\
\hline DM & $132(27.6 \%)$ & $26(5.4 \%)$ & $106(22.2 \%)$ & $0.73^{\mathrm{a}}$ \\
\hline HTN & $136(28.4 \%)$ & $23(4.8 \%)$ & $113(23.6 \%)$ & $0.18^{\mathrm{a}}$ \\
\hline Recovery time (days) & $15.48(8.3)$ & $17.46(9)$ & $14.95(8.1)$ & $0.008^{*}$ \\
\hline Hospitalization duration (days) & $6.89(7.2)$ & $8.97(9.4)$ & $6.25(6.2)$ & $0.003^{*}$ \\
\hline ICU admission & $42(8.7 \%)$ & 20 (20.2\%) & $22(5.5 \%)$ & $0.005^{* a}$ \\
\hline Death & $16(3.3 \%)$ & $4(0.8 \%)$ & $12(2.5 \%)$ & $0.70^{\mathrm{a}}$ \\
\hline
\end{tabular}

HTN, hypertension; DM, diabetes mellitus; SpO2, oxygen saturation; WBC, white blood cell; LDH, lactate dehydrogenase; CRP, C-reactive protein; ESR, erythrocyte sedimentation rate; ICU, intensive care unit

*Statistically significant ( $p$ value $<0.05$ ), reported as mean (standard deviation), all other variables reported as $\mathrm{N}(\%)$

${ }^{a}$ Chi-squared test is used; independent t-test or Mann-Whitney $\mathrm{U}$ test used for allother comparisons

patients should be considered high-risk patients for further medical planning.

\begin{abstract}
Abbreviations
COVID-19: The coronavirus disease; SARS-CoV-2: Severe acute respiratory syndrome coronavirus2; ACE2: Angiotensin-converting enzyme 2; SARS-CoV: Severe acute respiratory syndrome coronavirus; $\mathrm{CT}$ : Computed tomography; GGO: Ground glass opacity; RT-PCR: Real-time reverse-transcriptase-polymerase chain reaction; $\mathrm{SpO}_{2}$ : Oxygen saturation; RR: Respiratory rate; PR: Pulse rate; HTN: Hypertension; DM: Diabetes mellitus; WBC: White blood cell; CRP: C-reactive protein; ESR: Erythrocyte sedimentation rate; LDH: Lactate dehydrogenase; ICU: Intensive care unit; ARDS: Acute respiratory distress syndrome; RUL: Right upper lobe; RML: Right middle lobe; RLL: Right lower lobe; LUL: Left upper lobe; LLL: Left lower lobe.
\end{abstract}

\section{Acknowledgements}

The authors would like to thank all participants in this study.

\section{Authors' contributions}

NAY Conceptualized the project and developed the study methodology and also had the major role in investigation of radiological findings of patients and meanwhile Review \& Editing the manuscript. AHG developed the study methodology and conducted formal analysis meanwhile participated in writing the original draft. SS participated in Investigation, Resources, Visualization, Validation, Review \& Editing the manuscript. FJ participated in Investigation, Resources, Visualization, Validation, Review \& Editing the manuscript. SJ participated in Investigation, Resources, Visualization, Validation, Review \& Editing the manuscript. MH participated in Investigation, Resources, Visualization, Validation, Review \& Editing the manuscript. HEK participated in Investigation,
Resources, Visualization, Validation, Review \& Editing the manuscript. MS participated in Investigation, Resources, Visualization, Validation, Review \& Editing the manuscript. SADM participated in Investigation, Resources, Visualization, Validation, Review \& Editing the manuscript. MM participated in Investigation, Resources, Visualization, Validation, Review \& Editing the manuscript. MHajiabdolbaghi participated in Investigation, Resources, Visualization, Validation, Review \& Editing the manuscript. ZA participated in Investigation, Resources, Visualization, Validation, Review \& Editing the manuscript. HK participated in Investigation, Resources, Visualization, Validation, Review \& Editing the manuscript. MMM developed the study methodology and conducted formal analysis meanwhile participated in writing the original draft. LA was Project administrative and supervisor and acquired the funding for project and meanwhile she participated in writing and editing the manuscript. All authors read and approved the final manuscript.

\section{Funding}

This work was supported by a grant from Tehran University of Medical Sciences (Grant No: 47147), the fund is used for laboratory and imaging costs of patients.

Availability of data and materials

The datasets used and/or analysed during the current study are available from the corresponding author on reasonable request.

\section{Declarations}

\section{Ethics approval and consent to participate}

Study protocols and patients consent forms were reviewed and approved by the ethics committee of Tehran University of Medical Sciences (approval code: 
TUMS.VCR.REC.1399.138). All patients signed an informed consent form before entering the study.

\section{Consent for publication}

Not applicable.

\section{Competeing interest}

The authors declare no competing interest.

\section{Author details}

'Department of Radiology, Imam Khomeini Hospital, Tehran University of Medical Sciences, Tehran, Iran. ${ }^{2}$ Department of Radiology, Advanced Diagnostic and Interventional Radiology Research Center(ADIR), Tehran University of Medical Sciences, Tehran, Iran. ${ }^{3}$ Iranian Research Center for HIV/AIDS, Iranian Institute for Reduction of High-Risk Behaviors, Tehran University of Medical Sciences, Tehran, Iran. ${ }^{4}$ Department of Infectious Diseases, Imam Khomeini Hospital, Imam Khomeini Hospital Complex, Tehran University of Medical Sciences, Blv. Keshavarz, Tehran, Iran. ${ }^{5}$ Department of Pharmacotherapy, Imam Khomeini Hospital Complex, Tehran University of Medical Sciences, Tehran, Iran.

\section{Received: 2 August 2021 Accepted: 11 November 2021}

Published online: 18 November 2021

\section{References}

1. WHO Coronavirus (COVID-19) Dashboard [updated 12 July 2021. Available from: https://covid19.who.int/.

2. Wilder-Smith A, Chiew CJ, Lee VJ. Can we contain the COVID-19 outbreak with the same measures as for SARS? Lancet Infect Dis. 2020;20(5):e102-7.

3. Jia HP, Look DC, Shi L, Hickey M, Pewe L, Netland J, et al. ACE2 receptor expression and severe acute respiratory syndrome coronavirus infection depend on differentiation of human airway epithelia. J Virol. 2005;79(23):14614-21.

4. Zhu N, Zhang D, Wang W, Li X, Yang B, Song J, et al. A novel coronavirus from patients with pneumonia in China, 2019. N Engl J Med. 2020:382(8):727-33.

5. Joshi S, Parkar J, Ansari A, Vora A, Talwar D, Tiwaskar M, et al. Role of favipiravir in the treatment of COVID-19. Int J Infect Dis. 2021;102:501-8.

6. Fisher KA, Olson SM, Tenforde MW, SelfWH, Wu M, Lindsell CJ, et al. Symptoms and recovery among adult outpatients with and without COVID-19 at 11 healthcare facilities-July 2020, United States. Influenza Other Respir Viruses. 2021;15(3):345-51.

7. Dehghani Firouzabadi F, Dehghani Firouzabadi M, Ghalehbaghi B, Jahandideh H, Roomiani M, Goudarzi S. Have the symptoms of patients with COVID-19 changed over time during hospitalization? Med Hypotheses. 2020;143:110067.

8. Firouzabadi MD, Firouzabadi FD, Goudarzi S, Jahandideh H, Roomiani M. Has the chief complaint of patients with COVID-19 disease changed over time? Med Hypotheses. 2020;144:109974.

9. Inciardi RM, Lupi L, Zaccone G, Italia L, Raffo M, Tomasoni D, et al. Cardiac involvement in a patient with coronavirus disease 2019 (COVID-19). JAMA Cardiol. 2020;5(7):819-24.

10. Pei G, Zhang Z, Peng J, Liu L, Zhang C, Yu C, et al. Renal Involvement and Early Prognosis in Patients with COVID-19 Pneumonia. J Am Soc Nephrol. 2020;31(6):1157-65.

11. Rothan HA, Byrareddy SN. The epidemiology and pathogenesis of coronavirus disease (COVID-19) outbreak. J Autoimmun. 2020;109:102433.

12. Ye Q, Wang B, Mao J. The pathogenesis and treatment of the 'Cytokine Storm' in COVID-19. J Infect. 2020;80(6):607-13.

13. Shi $H$, Han $X$, Jiang $N$, Cao Y, Alwalid O, Gu J, et al. Radiological findings from 81 patients with COVID-19 pneumonia in Wuhan, China: a descriptive study. Lancet Infect Dis. 2020;20(4):425-34

14. Chung M, Bernheim A, Mei X, Zhang N, Huang M, Zeng X, et al. CT imaging features of 2019 novel coronavirus (2019-nCoV). Radiology. 2020;295(1):202-7.

15. Jafari S, Tabary M, Eshraghi S, Araghi F, Aryannejad A, Mohammadnejad

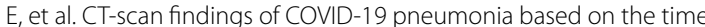

elapsed from the beginning of symptoms to the CT imaging evaluation: a descriptive study in Iran. Rom J Intern Med. 2020;58(4):242-50.

16. Lescure FX, Bouadma L, Nguyen D, Parisey M, Wicky PH, Behillil S, et al Clinical and virological data of the first cases of COVID-19 in Europe: a case series. Lancet Infect Dis. 2020:20(6):697-706.

17. Hansell DM, Bankier AA, MacMahon H, McLoud TC, Müller NL, Remy J. Fleischner society: glossary of terms for thoracic imaging. Radiology. 2008;246(3):697-722.

18. Chang YC, Yu CJ, Chang SC, Galvin JR, Liu HM, Hsiao CH, et al. Pulmonary sequelae in convalescent patients after severe acute respiratory syndrome: evaluation with thin-section CT. Radiology. 2005;236(3):1067-75.

19. Salvatore C, Roberta F, Angela L, Cesare P, Alfredo C, Giuliano G, et al. Clinical and laboratory data, radiological structured report findings and quantitative evaluation of lung involvement on baseline chest $C T$ in COVID-19 patients to predict prognosis. Radiol Med. 2021;126(1):29-39.

20. Zhang J, Meng G, Li W, Shi B, Dong H, Su Z, et al. Relationship of chest CT score with clinical characteristics of 108 patients hospitalized with COVID-19 in Wuhan, China. Respir Res. 2020;21(1):180.

21. Oliviero A, de Castro F, Coperchini F, Chiovato L, Rotondi M. COVID-19 pulmonary and olfactory dysfunctions: is the chemokine CXCL10 the common denominator? Neuroscientist. 2021;27(3):214-21.

22. Cai W, Liu T, Xue X, Luo G, Wang X, Shen Y, et al. CT Quantification and machine-learning models for assessment of disease severity and prognosis of COVID-19 Patients. Acad Radiol. 2020;27(12):1665-78.

23. Li K, Wu J, Wu F, Guo D, Chen L, Fang Z, et al. The clinical and chest CT features associated with severe and critical COVID-19 pneumonia. Invest Radiol. 2020;55(6):327-31.

24. Aalinezhad M, Alikhani F, Akbari P, Rezaei MH, Soleimani S, Hakamifard A. Relationship between CT severity score and capillary blood oxygen saturation in patients with COVID-19 infection. Indian J Crit Care Med. 2021:25(3):279-83.

25. Osman AM, Farouk S, Osman NM, Abdrabou AM. Longitudinal assessment of chest computerized tomography and oxygen saturation for patients with COVID-19. Egyp J Radiol Nuclear Med. 2020;51(1):1-11.

26. Yu Q, Wang Y, Huang S, Liu S, Zhou Z, Zhang S, et al. Multicenter cohort study demonstrates more consolidation in upper lungs on initial CT increases the risk of adverse clinical outcome in COVID-19 patients. Theranostics. 2020;10(12):5641-8.

27. Salahshour F, Mehrabinejad MM, Nassiri Toosi M, Gity M, Ghanaati H, Shakiba $M$, et al. Clinical and chest CT features as a predictive tool for COVID-19 clinical progress: introducing a novel semi-quantitative scoring system. Eur Radiol. 2021;2021:1-11.

28. Nagra D, Russell M, Yates M, Galloway J, Barker R, Desai SR, et al. COVID-19: opacification score is higher in the right lung and right lung involvement is a better predictor of ICU admission. Eur Respir J. 2020;56:6.

29. Liu Z, Jin C, Wu CC, Liang T, Zhao H, Wang Y, et al. Association between initial chest CT or clinical features and clinical course in patients with coronavirus disease 2019 pneumonia. Korean J Radiol. 2020;21(6):736-45.

30. Ahlstrand E, Cajander S, Cajander P, Ingberg E, Löf E, Wegener M, et al. Visual scoring of chest CT at hospital admission predicts hospitalization time and intensive care admission in Covid-19. Infect Dis (Lond). 2021;2021:1-11.

31. Jalali A, Karimialavijeh E, Babaniamansour P, Aliniagerdroudbari E, Babaniamansour S. Predicting the 30-day adverse outcomes of non-critical new-onset COVID-19 patients in emergency departments based on their lung CT scan findings; a pilot study for derivation an emergency scoring tool. Front Emerg Med. 2021;5:e40.

\section{Publisher's Note}

Springer Nature remains neutral with regard to jurisdictional claims in published maps and institutional affiliations. 